\title{
Patterns of RAPD markers and heavy metal concentrations in Perna viridis (L.), collected from metal-contaminated and uncontaminated coastal waters: Are they correlated with each other?
}

\begin{abstract}
Genetic variation due to heavy metal contamination has always been an interesting topic of study. Because of the numerous contaminants being found in coastal and intertidal waters, there is always much discussion and argument as to which contaminant(s) caused the variations in the genetic structures of biomonitors. This study used a Single Primer Amplification Reaction (SPAR) technique, namely Random Amplified Polymorphic DNA (RAPD), to determine the genetic diversity of the populations of the green-lipped mussel Perna viridis collected from a metal-contaminated site at $\mathrm{Kg}$. Pasir Puteh and those from four relatively uncontaminated sites (reference sites). Heavy metal levels $(\mathrm{Cd}, \mathrm{Cu}, \mathrm{Pb}$, and $\mathrm{Zn}$ ) were also measured in the soft tissues and byssus of the mussels from all the sites. Cluster analyses employing UPGMA based on the RAPD markers grouped the populations into two major clusters; the Bagan Tiang, Pantai Lido, Pontian, and Kg. Pasir Puteh populations were in one cluster, while the Sg. Belungkor population clustered by itself. This indicated that the genetic diversity based on bands resulting from the use of all four RAPD primers on P. viridis did not indicate its potential use as a biomarker of heavy metal pollution in coastal waters. However, based on a correlation analysis between a particular metal and a band resulting from a specific RAPD primer revealed some significant $(\mathrm{P}<0.01)$ correlations between the primers and the heavy metal concentrations in the byssus and soft tissues. Thus, the correlation between a particular metal and the bands resulting from the use of a specific RAPD primer on P. viridis could be used as biomonitoring tool of heavy metal pollution.
\end{abstract}

Keyword: Genetics, heavy metal contamination 